\title{
Side Effect of some Acaricides on Three Predators of Tetranychus urticae Koch
}

\author{
Ahmed, Y. M. ${ }^{1}$; A. M. El-Adawy ${ }^{2}$; A. M. A. Mostafa ${ }^{1}$ and Rehab I. Hafez ${ }^{2}$ \\ ${ }^{1}$ Plant Protection Department, Faculty of Agriculture, Suez Canal University, Ismailia, Egypt. \\ ${ }^{2}$ Plant Protection Research Institute, Agricultural Research Center, Giza, Egypt.
}

Received: $25 / 12 / 2015$

\begin{abstract}
The toxicity of six acaricides namely, ethion, bifenazate, chlorfenapyr, abamectin, diafenthiuron and hexythiazox, presented different chemical groups, were determined on each of the two spotted spider mites Tetranychus urticae Koch (Acari: Tetranychidae) and three of its predators; Phytoseiulus persimilis Athias-Henriot (Acari: Phytoseiidae), Scolothrips longicornis Priesner (Thysanoptera: Thripidae) and Stethorus gilvifrons Mulsant (Coleoptera: Coccinellidae). The obtained results revealed that abamectin $(0.53 \mathrm{ppm})$, ethion (15.2 ppm), abamectin, (19.0 ppm) and diafenthiuron $(14.0 \mathrm{ppm})$ were the most toxic acaricides on T. urticae, P. persimilis, S. longicornis and $S$. gilvifrons, respectively at $\mathrm{LC}_{50}$ level. Based on $\mathrm{LC}_{50}$ and $\mathrm{LC}_{90}$ of the tested acaricides on the studied predators, selective toxicity ratios were calculated at the same former levels. All the tested acaricides were safe except ethion at $\mathrm{LC}_{50}$ and bifenazate at $\mathrm{LC}_{90}$ on P.persimilis, bifenazate and hexythiazox were harmful at $\mathrm{LC}_{50}$; whereas chlorfenapyr and abamectin were safe at $\mathrm{LC}_{90}$ on $S$. longicornis. Regarding $S$. gilvifrons, all tested acaricides were safe at $\mathrm{LC}_{90}$ except bifenazate and diafenthiuron at $\mathrm{LC}_{50}$ and bifenazate at $\mathrm{LC}_{90}$. The selectivity ratios (s.r) at $\mathrm{LC}_{50}$ and $\mathrm{LC}_{90}$ levels were incorporated in one parameter as general selective toxicity ratio. The obtained values were $2.04,1.35,0.28,0.006,1.74$ and 0.41 for $P$. persimilis inethion, bifenazate, chlorfenapyr, abamectin, diafenthiuron and hexythiazox treatments, respectively. The respective values were $0.506,0.715,4.0,3.78,0.025$ and 1.496 for $S$. longicornis and $0.01,0.53,1.68,1.59,0.04$ and 0.59 for $S$. gilvifrons.
\end{abstract}

Keywords: Acaricides, Tetranychus urticae, Phytoseiulus persimilis, Scolothrips longicornis, Stethorus gilvifrons

\section{INTRODUCTION}

The two-spotted spider mite (TSSM), Tetranychus urticae Koch (Acari: Tetranychidae) is one of the most serious pests, causing yield losses to many horticultural, ornamental and agronomic crops. A major problem in controlling T. urticae is its resistance to many acaricides (Puinean et al., 2010). Resistance to acaricides in $T$. urticae spreads rapidly. So, biological control tactics are crucial to manage spider mite populations (Gerson and Weintraub, 2006). Phytoseiulus persimilis AthiasHenriot (Acari: Phytoseiidae) is an effective predator for controlling T. urticae. Therefore, it is required to evaluate the effect of frequent application of acaricides on some biological parameters of this predator (Sanatgar et al,. 2011). Also, Scolothrips longicornis Priesner (Thysanoptera: Thripidae) is an important predator and a good candidate for biological control of several spider mites (Nakagawa, 1993; Kishimoto, 2002; Zhang et al., 2005). Many species of Stethorus spp. (Coleoptera: Coccinellidae) feed on wide range of tetranychid species. Stethorus keralicus Kapur and Stethorus gilvifrons (Mulsant) are considered as specialists that feed on T. urticae (Aydemir and Toros, 1990).

The aim of the present study is to clarify the side effect of certain common use acaricides on $P$. persimilis, $S$. longicornis and $S$. gilvifrons and to determine the safest acaricides to use in IPM program of T. urticae.

\footnotetext{
MATERIALS AND METHODS

1. Chemical used:

1.1- Ethion

Trade name: Endo $50 \%$

Common name: Ethion

IUPAC name: O, O, O, O'- tetraethyl S, S'- methylene bis (phosphorodithioate).
}

Recommended concentration: $600 \mathrm{ml} / 100$ L.W

\section{2- Bifenazate}

Trade name: Acramite $48 \%$

Common Name: Bifenazate.

IUPAC name: isopropyl 3-(4- methoxybiphenyl - 3yl) carbazate.

Recommended concentration: $50 \mathrm{ml} / 100 \mathrm{~L}$.

1.3- Chlorfenapyr

Trade name: Challenger 36\% S.C

Common name: Chlorfenapyr

IUPAC name: 4-bromo-2- (4-chlorophenyl)-1(ethoxymethyl)-5-trifluoromethylpyrrole $\quad-3 \quad-$ carbonitrile.

Recommended concentration: $45 \mathrm{ml} / 100 \mathrm{~L}$.

1.4-Abamectin

Trade name: Avermectin 3.6\% E.C

Common name: Abamectin

IUPAC name: 5-0 dimethyl-25-de-1 methylpropyl-25(1-methylethyl) Avermectins A1a (R=CH3)-B1b

Recommended concentration: $45 \mathrm{ml} / 100 \mathrm{~L} . \mathrm{W}$

\section{5-Dafenthiuron}

Trade name: Pegasus 50\% W.P

Common name: Diafenthiuron

IUPAC name: 1-tert- butyl- 3- (2, 6 di-isopropyl -4phenoxyphenyl) thiourea.

Recommended concentration: $120 \mathrm{ml} / 100 \mathrm{~L} . \mathrm{W}$

\section{6- Hexythiazox}

Trade name: Nissorun 50\% W.P

Common name: Hexythiazox

IUPAC name: (4RS, 5RS)-5-(4- Chlorophenyl)- Ncyclohexyl-4- methyl- 2- oxo-1,3 thiazolidine-3 carboxamide.

Recommended concentration: $40 \mathrm{ml} / 100 \mathrm{~L} . \mathrm{W}$

2- Maintenance of the colonies:

a. T. urticae:

For establishing a colony of $T$. urticae in the laboratory, the technique of Guirguis et al. (1977) was 
followed. The mites were collected from infested leaves of the castor bean, Ricinus communis trees grown at the Experimental Farm of Ismailia Agricultural Research Station, Ismailia, Egypt.

One hundred adult females of $T$. urticae were transferred with a fine brush (Pelikan brush No. 000) to sweet potato leaves. Sweet potato cuttings, each holding about 8 leaves, were washed under running tap water and then the basal portion of these cuttings was inserted in water in $250 \mathrm{ml}$ glass jar. Each jar contained three sweet potato cuttings. The colony was established with three jars. The sweet potato cuttings were changed twice a week in summer, and once a week in winter or when it was necessary.

The colony was kept in special cage $(60 \times 60 \times 60 \mathrm{~cm})$ under laboratory conditions of $25 \pm 2^{\circ} \mathrm{C} ; 65 \pm 5 \%$ relative humidity and $12 \mathrm{hrs}$ daily illuminations by using fluorescent tubes of 40-60 watt. The colony was kept away from any pesticide contamination for six months before used in experiment.

\section{b. P. persimilis}

The original samples of $P$. persimilis were received from the Plant Protection Division, Faculty of Environmental and Agricultural Sciences, Al-Arish, Suez Canal University, Egypt. The methodology of Shaw (1982) was used for rearing $P$. persimilis. $P$. persimilis was transferred with a fine brush on the sweet potato cutting harboring $T$. urticae. The colony of the predator was supplied with TSSM, when it was necessary.

\section{c. S. longicornis}

S. longicornis was collected from castor plants, at Ismailia Agricultural Research Station. Infested castor bean leaves with $T$. urticae that accompanied with $S$. longicornis were cut and transferred to the laboratory of Plant Protection in Ismailia Agricultural Research station. Each glass tube $(35 \mathrm{~cm}$ diameter $\times 10 \mathrm{~cm}$ high), was provided with a piece of cabbage leaf as an ovipositional substrate. Ten adult females of $S$. longicornis were collected from infested castor leaves and transferred to each tube, which contained a sweet potato leaf heavily infested with $T$. urticae. These tubes were covered with a fastened muslin piece. Cabbage leaves harboring deposited eggs were kept in Petri dishes (9 $\mathrm{cm}$ diameter) under laboratory conditions of $25 \pm 2^{\circ} \mathrm{C}$ and $65 \pm 5 \%$ (R.H).

\section{d. S. gilvifrons}

The original samples of $S$. gilvifrons were collected from the wild trees of castor bean, at Ismailia district. The heavily infested leaves with $T$. urticae, and associated with the coccinellid predator $S$. gilvifrons were picked and placed in paper bags and transferred to the laboratory of Plant Protection Division, Agricultural Research Station, Ismailia. The method proposed by Sarhan et al. (1989) was followed for rearing of this predator. Adults of $S$. gilvifrons were kept in glass tubes $(2 \times 8 \mathrm{~cm})$ covered with muslin. Each tube was provided with sweet potato leaves heavily infested with $T$. urticae as a food supply for the enclosed predator individuals. Leaves, harboring newly deposited eggs of the predator, were collected and kept in Petri dishes $(9 \mathrm{~cm}$ in diameter), and examined daily until hatching. Each newly hatched larva was placed in a Petri dish and provided with pieces of sweet potato leaf infested with T. urticae. The amount of food was increased daily with the larval development until pupation took place. Pupae were kept separately in glass tubes $(2 \times 8 \mathrm{~cm})$ covered with a piece of muslin till adult emergence. Newly emerged adults were sexed and each couple was kept in a petri-dish.

\section{2- The toxicity of the tested acaricides:}

Direct spray technique was used to test the toxicity of the tested acaricides to T. urticae and its tested predators. In this respect, small circular leaf disc (1 inch in diameter) was taken from sweet potato leaves and placed in Petridishes lined with water saturated cotton wool. Twenty females of T. urticae were transferred on the lower surface of each disc. As for the tested predators, twenty adults of each tested predator were separately transferred on the lower surface of each leaf disc heavily infested with $T$. urticae. Each Petridish contained four discs. Five concentrations of the tested acaricides were used to draw toxicity line. Discs were sprayed with a constant amount of the acaricides solution determined by spraying pressure for three seconds by means of glass manual atomizer. These Petri dishes were kept under laboratory conditions of $25 \pm 2^{\circ} \mathrm{C}$ and $65 \pm 5 \%$ R.H. The criterion for mortality was failure of mite to respond positively by leg movement following light prodding with a fine brush. Untreated leaf discs served as control. Four Petri dishes were used for each treated and untreated discs as replicates. The mortality was recorded 48 hours after treatment.

Abbot's formula (1925) was used to get correction for natural mortality. Lines of toxicity were statistically analyzed according to the method described by Finney (1952). The relative efficiency of the tested compounds was determined according to Sun (1950) as follows

$$
\begin{aligned}
& \text { Toxicity index }=\frac{\text { LC50 of the compound } A}{\text { LC50 of the compound } B} \times 100 \\
& \mathrm{~A} \longrightarrow \text { the most effective compound } \\
& \mathrm{B} \longrightarrow \text { the other tested compound }
\end{aligned}
$$

To calculate the general selective toxicity ratio of the tested acaricides, the method of Abdel-Aal et al. (1979) modified by El-Adawy et al. (2000) was used as follow:

The selectivity ratio (s.r) at $\mathrm{LC}_{90}$ level can be combined with $\mathrm{LC}_{50}$ in one parameter (general selective toxicity ratio) by employing the following equation:

$$
\text { G.S.T.R }=\text { experimental s.r at LC } 50 \times(10) \frac{1.28}{\frac{b p-b m}{b \times b m}}
$$

Where are:

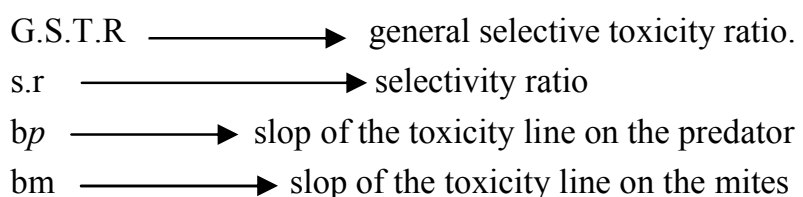


To calculated the selectivity ratio (s.r) of the tested acaricides at $\mathrm{LC}_{50}$ level used:

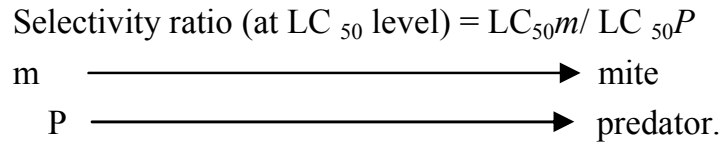

\section{RESULTS AND DISCUSSION}

Toxicity of acaricides to $T$. urticae:

Data in Table (1) showed the descending order of the toxicity of the tested acaricides on T. urticae. The $\mathrm{LC}_{50}$ values were $0.53,5.9,20.6,23.7,24.7$ and 39.9 ppm for abamectin, chlorfenapyr, hexythiazox, diafenthiuron, ethion and bifenazate, respectively.

Concerning the $\mathrm{LC}_{90}$, the most effective compound against $T$. urticae was abamectin $(4.26 \mathrm{ppm})$, followed by chlorfenapyr (52.4 ppm), diafenthiuron (120.7 ppm), ethion (125.9 ppm), hexythiazox (167.2 ppm), and bifenazate $(661.1 \mathrm{ppm})$. The order of the tested acaricides at $\mathrm{LC}_{90}$ differed to that observed based on the $\mathrm{LC}_{50}$ values. This refers to the variation of slop values of the tested acaricides. On the bases of slope values, diafenthiuron had the steepest toxicity line $(1.81 \mathrm{ppm})$, whereas bifenazate had the flattest one $(1.05 \mathrm{ppm})$. The other values came between the two former values, (1.41 ppm) for each of abamectin and hexythiazox, (1.76 ppm) for chlorfenapyr and (1.8 ppm) for ethion.

Concerning the toxicity index at $\mathrm{LC}_{50}$, the most effective compound was abamectin (toxicity index $=$ 100) followed descendingly by chlorfenapyr (8.96 ppm), hexythiazox (2.56 ppm), diafenthiuron (2.22 $\mathrm{ppm})$, ethion (2.14 ppm) and bifenazate (1.32 ppm); whereas the values at $\mathrm{LC}_{90}$ level were $100,8.12,3.52$, $3.38,2.54$ and $0.64 \mathrm{ppm}$ for abamectin, chlorfenapyr, diafenthiuron, ethion, hexythiazox and bifenazate ,respectively. The toxicity index reflects the differences among the tested acaricides in their toxicity.

Clearly, abamectin had the most toxic effect against the adult females of TSSM; whereas the bifenazate had the lowest effect. Such results are in agreement with those obtained by Szwejda (1993) and El-Adawy et al. (1995). Szwejda (1993) stated that Abamectin, Fenapyred, Acrinatrin and Difenthiuron achieved excellent control with percentage of mortality reached more than 98\%, against Tetranychus urticae and Tetranychus cinnabarinus Boisd. Also, El-Adawy et al. (1995) reported that Abamectin reduced TSSM population by $79.8 \%$ through 21 days.

Table (1): Toxicity of certain acaricides to the adult females of T. urticae

\begin{tabular}{|c|c|c|c|c|c|}
\hline \multirow{2}{*}{ Acaricides } & \multirow{2}{*}{$\begin{array}{l}\mathbf{L C}_{50} \\
\mathbf{p p m}\end{array}$} & \multirow{2}{*}{$\begin{array}{l}\mathbf{L C}_{90} \\
\mathbf{p p m}\end{array}$} & \multirow{2}{*}{ Slope } & \multicolumn{2}{|c|}{ Toxicity index } \\
\hline & & & & $\mathbf{L C}_{50}$ & $\mathrm{LC}_{90}$ \\
\hline Ethion & 24.7 & 125.9 & 1.8 & 2.14 & 3.38 \\
\hline Bifenazate & 39.9 & 661.1 & 1.05 & 1.32 & 0.64 \\
\hline Chlorfenapyr & 5.9 & 52.4 & 1.76 & 8.96 & 8.12 \\
\hline Abamectin & 0.53 & 4.26 & 1.41 & 100 & 100 \\
\hline Diafenthiuron & 23.7 & 120.7 & 1.81 & 2.22 & 3.52 \\
\hline Hexythiazox & 20.6 & 167.2 & 1.41 & 2.56 & 2.54 \\
\hline
\end{tabular}

\section{The selectivity of the tested acaricides On $P$. persimilis}

Data in Table (2) showed that ethion is the most toxic compound to $P$. persimilis at $\mathrm{LC}_{50}(15.2 \mathrm{ppm})$ followed by abamectin (30.9 ppm), bifenazate (45.6 ppm), chlorfenapyr (45.8 ppm), hexythiazox (74.3 ppm) and diafenthiuron $(76.6 \mathrm{ppm})$. At $\mathrm{LC}_{90}$, the value were ethion $(170.5 \mathrm{ppm})$, chlorfenapyr (280.6 ppm), bifenazate $(383.3 \mathrm{ppm})$, hexythiazox (736.0 ppm), diafenthiuron (886.1 ppm) and abamectin (1020.4 ppm).

On the bases of slope values, chlorfenapyr had the steepest toxicity line (1.6); whereas abamectin had the flattest one (0.8).

According the selectivity ratio, the least toxic ratio was found for abamectin at 0.01 and $0.004 \mathrm{ppm}$ at for $\mathrm{LC}_{50}$ and $\mathrm{LC}_{90}$ levels, respectively; whereas the highest toxic ratio was shown by ethion $1.6 \mathrm{ppm}$ at $\mathrm{LC}_{50}$ level and bifenazate $1.7 \mathrm{ppm}$ at $\mathrm{LC}_{90}$ Level.
The values of the general selectivity ratio to $P$. persimilis were $0.006,0.28,0.41,1.35,1.74$ and 2.04 ppm for Abamectin, Chlorfenapyr, Hexythiazox, Bifenazate, Diafenthiuron and Ethion, respectively. It is obvious that abamectin had the lowest general selective ratio $(0.006 \mathrm{ppm})$; whereas ethion had the highest value (2.04 ppm) for P. persimilis.

Based on the general selective ratio, it is clear that abamectin, Chlorfenapyr, and hexythiazox can be considered as the safest tested acaricides for $P$. persimilis since the values were less than $1 \%$. Such results are in agreement with those obtained earlier (Ahnet al., 2004; Kim and Yoo, 2002; White, 2004).

Also, Acramite (bifenazate) wad less toxic to adult females and immature stages of $P$. persimilis than to adult female and immature stages of TSSM. 
Table (2): The toxicity of certain acaricides to $T$. urticae and its predator $P$. persimilis.

\begin{tabular}{|c|c|c|c|c|c|c|c|c|c|}
\hline \multirow{2}{*}{ Acaricides } & \multicolumn{3}{|c|}{ T. urticae } & \multicolumn{3}{|c|}{ P. persimilis } & \multicolumn{2}{|c|}{ Selectivity ratio* } & \multirow{2}{*}{$\begin{array}{c}\text { General } \\
\text { selective ratio }\end{array}$} \\
\hline & $\mathbf{L C}_{50}$ & $\mathrm{LC}_{90}$ & Slope (b) & $\mathbf{L C}_{50}$ & $\mathrm{LC}_{90}$ & Slope (b) & $\mathbf{L C}_{50}$ & $\mathbf{L C}_{90}$ & \\
\hline Ethion & 24.7 & 125.9 & 1.8 & 15.2 & 170.5 & 1.2 & 1.6 & 0.7 & 2.04 \\
\hline Bifenazate & 39.9 & 661.1 & 1.05 & 45.6 & 383.3 & 1.3 & 0.8 & 1.7 & 1.35 \\
\hline Chlorfenapyr & 5.9 & 52.4 & 1.76 & 45.8 & 280.6 & 1.6 & 0.1 & 0.2 & 0.28 \\
\hline Abamectin & 0.53 & 4.26 & 1.41 & 30.9 & 1020.4 & 0.8 & 0.01 & 0.004 & 0.006 \\
\hline Diafenthiuron & 23.7 & 120.7 & 1.81 & 76.6 & 886.1 & 1.2 & 0.3 & 0.1 & 1.74 \\
\hline Hexythiazox & 20.6 & 167.2 & 1.41 & 74.3 & 736.0 & 1.2 & 0.2 & 0.2 & 0.41 \\
\hline
\end{tabular}

*s.r (selectivity ratio) $=\mathrm{LC}_{50}$ of $\mathrm{m}$. / $\mathrm{LC}_{50}$ of $\mathrm{P}$.

\section{On S. longicornis}

Concerning the side effect of the tested acaricides on $S$. longicornis, data in Table (3) showed that abamectin had the highest toxicity at the LC ${ }_{50}(19.0$ $\mathrm{ppm})$, followed by hexythiazox (20.3 $\mathrm{ppm})$, diafenthiuron (27.2 ppm), ethion (27.7 ppm), chlorfenapyr (28.4 ppm) and bifenazate (35.9 ppm); Whereas the $\mathrm{LC}_{90}$ Values were 75.11, 105.0, 105.0, 128.3, 169.2 and $271.0 \mathrm{ppm}$ for hexythiazox, ethion, diafenthiuron, abamectin, chlorfenapyr and bifenazate, respectively. On the basis of slope values, hexythiazox had the steepest toxicity line (2.2); whereas bifenazate had the flattest one (1.4).

As for selectivite ratio at $\mathrm{LC}_{50}$, data in Table (3) showed that ethion, chlorfenapyr, abamectin and diafenthiuron have s.rvalues less than one, which indicated that the tested acaricides are safe to the predators. However, at $\mathrm{LC}_{90}$ level,all tested acaricides had values morethan one except chlorfenapyr (0.30) and abamectin (0.03).

Regarding the general selective toxicity ratio, these values were $0.025,0.506,0.715,1.496,3.78$ and 4.0 ppm for Diafenthiuron, ethion, bifenazate, hexythiazox, abamectin and chlorfenapyr, respectively. It is obvious that diafenthiuron had the lowest general selective ratio $(0.025 \mathrm{ppm})$; whereas Chlorfenapyr had the highest one (4.0 ppm).

So, it is clear that all tested acaricides except abamectin, Chlorfenapyr, and hexythiazox can be considered as safe acaricides for S. longicornis.

El-Esnawy (2006) showed that abamectin was the most effective acaricides on T. urticae and had the highest toxicity on its predator $S$. longicornis.

Table (3): The toxicity of certain acaricides to T. urticae and its predator S. longicornis.

\begin{tabular}{|c|c|c|c|c|c|c|c|c|c|}
\hline \multirow{2}{*}{ Acaricides } & \multicolumn{3}{|c|}{ T. urticae } & \multicolumn{3}{|c|}{ S. longicornis } & \multicolumn{2}{|c|}{ Selectivity ratio * } & \multirow{2}{*}{$\begin{array}{c}\text { General } \\
\text { selective } \\
\text { ratio }\end{array}$} \\
\hline & $\mathbf{L C}_{50}$ & $\mathrm{LC}_{90}$ & Slope (b) & $\mathbf{L C}_{50}$ & $\mathbf{L C}_{90}$ & Slope(b) & $\mathbf{L C}_{\mathbf{5 0}}$ & $\mathrm{LC}_{90}$ & \\
\hline Ethion & 24.7 & 125.9 & 1.8 & 27.7 & 105.0 & 2.1 & 0.8 & 1.19 & 0.506 \\
\hline Bifenazate & 39.9 & 661.1 & 1.05 & 35.9 & 271.0 & 1.4 & 1.11 & 2.43 & 0.715 \\
\hline Chlorfenapyr & 5.9 & 52.4 & 1.76 & 28.4 & 169.2 & 1.6 & 0.19 & 0.30 & 4.0 \\
\hline Abamectin & 0.53 & 4.26 & 1.41 & 19.0 & 128.3 & 1.5 & 0.02 & 0.03 & 3.78 \\
\hline Diafenthiuron & 23.7 & 120.7 & 1.81 & 27.2 & 105.0 & 2.1 & 0.87 & 1.14 & 0.025 \\
\hline Hexythiazox & 20.6 & 167.2 & 1.41 & 20.3 & 75.11 & 2.2 & 1.01 & 2.22 & 1.496 \\
\hline
\end{tabular}

$*_{\text {s.r }}($ selectivity ratio $)=\mathrm{LC}_{50} \mathrm{ofm} . / \mathrm{LC}_{50}$ of $\mathrm{P}$. 


\section{On S. gilvifrons}

Data in Table (4) showed the values of $\mathrm{LC}_{50}$ for $S$. gilvifrons were 14.0, 24.1, 32.7, 38.7, 56.6 and 62.2 ppm for diafenthiuron, abamectin, bifenazate, chlorfenapyr, ethion and hexythiazox, respectively; Whereas, values at $\mathrm{LC}_{90}$ level indicated that abamectin was the most toxiccompound (102.0 ppm), followed bychlorfenapyr (109.9 ppm), bifenazate (152.9 ppm), diafenthiuron (153.1 ppm), hexythiazox (263.9 ppm) and ethion (2633.3ppm). As for the slope values, ethion had the flattest slope $(0.7 \mathrm{ppm})$; whereas chlorfenapyr had the steepest one (2.8 ppm).

According to the selectivity ratio, the least toxic ratio was found for abamectin $0.02 \mathrm{ppm}$ at $\mathrm{LC}_{50}$ level; whereas ethion and abamectin $(0.04 \mathrm{ppm})$ were the least at $\mathrm{LC}_{90}$ level. The highest toxic ratio was shown by diafenthiuron $1.69 \mathrm{ppm}$ at $\mathrm{LC}_{50}$ and bifenazate $4.32 \mathrm{ppm}$ at $\mathrm{LC}_{90}$.
About the general selective ratio, the values of ethion, bifenazate, chlorfenapyr, abamectin, diafenthiuron, and hexythiazox were $0.01,0.53,1.68$, $1.59,0.04$, and $0.59 \mathrm{ppm}$, respectively. It is obvious that ethion had the lowest general selective ratio $(0.01 \mathrm{ppm})$; whereas chlorfenapyr had the highest one (1.68 ppm).

So, it is clear that all tested acaricides except abamectin and chlorfenapyr can be considered safe for S. gilvifrons.

It could be concluded that abamectin, chlorfenapyr, and hexythiazox could be used to control TSSM in the presence of $P$. persimilis. In the presence of $S$. longicornis with $T$. urticae, ethion, bifenazate, and diafenthiuron were the most recommended acaricides for TSSM control. Meanwhile, ethion, bifenazate, diafenthiuron, hexythiazox are preferable to be applied on the presence of S. gilvifrons.

Table (4): The toxicity of certain acaricides to T. urticae and its predator S. gilvifrons.

\begin{tabular}{|c|c|c|c|c|c|c|c|c|c|}
\hline \multirow{2}{*}{ Acaricides } & \multicolumn{3}{|c|}{ T. urticae } & \multicolumn{3}{|c|}{ S. gilvifrons } & \multicolumn{2}{|c|}{$\begin{array}{c}\text { Selectivity } \\
\text { ratio** }\end{array}$} & \multirow{2}{*}{$\begin{array}{c}\text { General } \\
\text { selective } \\
\text { ratio }\end{array}$} \\
\hline & $\mathbf{L C}_{50}$ & $\mathbf{L C}_{90}$ & Slope (b) & $\mathbf{L C}_{50}$ & $\mathbf{L C}_{90}$ & Slope (b) & $\mathbf{L C}_{50}$ & $\mathrm{LC}_{90}$ & \\
\hline Ethion & 24.7 & 125.9 & 1.8 & 56.5 & 2633.3 & 0.7 & 0.43 & 0.04 & 0.01 \\
\hline Bifenazate & 39.9 & 661.1 & 1.05 & 32.7 & 152.9 & 1.9 & 1.22 & 4.32 & 0.53 \\
\hline Chlorfenapyr & 5.9 & 52.4 & 1.76 & 38.7 & 109.9 & 2.8 & 0.15 & 0.47 & 1.68 \\
\hline Abamectin & 0.53 & 4.26 & 1.41 & 24.1 & 102.0 & 2.0 & 0.02 & 0.04 & 1.59 \\
\hline Diafenthiuron & 23.7 & 120.7 & 1.81 & 14.0 & 153.1 & 1.2 & 1.69 & 0.78 & 0.04 \\
\hline Hexythiazox & 20.6 & 167.2 & 1.41 & 62.2 & 263.9 & 2.0 & 0.33 & 0.63 & 0.59 \\
\hline
\end{tabular}

*s.r (selectivity ratio $)=\mathrm{LC}_{50} \mathrm{ofm} . / \mathrm{LC}_{50}$ of $\mathrm{P}$.

\section{REFERENCES}

Abbot, W. S. (1925). Method of computing effectiveness of all insecticides. J. Econ. Entomol, 18: 265-267.

Abdel-Aal, Y. A. I., A. M. K. El-Sayed, A. A. Negm, M. H. Hossein and A. H. El-Sabae (1979). The relative toxicity of certain insecticides to Spodoptera littoralis (Boisd) and Coccinella undecimpunctata L. International Pest control, July/Augst: 79-82.

Ahn, K., SY Lee, K Lee, Y Lee and G Kim (2004). Selective toxicity of pesticides to the predatory mite, Phytoseiulus persimilis and control effects of the two-spotted spider mite, Tetranychus urticae by predatory mite and pesticide mixture on rose. Korean J. Appl. Entomol., 43:71-79.

Aydemir, M. and S. Toros (1990). Natural enemies of Tetranychus urticae on bean plant in Erzinca Proceedings of the Second Turkish National Congress of Biological control, 261-271.

El-Adawy, A.M., H.M. Yousri, Y.H. Ahmed and T. A. El-Sharkawy (1995). Effect of some acaricides and biocides Naturalis-L (Beauveriabassiana) on the two spotted mites Tetranychus urticae Koch infesting cucumber under plastic house condition. $6^{\text {th }}$ Nat. Conf. of Pest and Dis. of Veg. and fruits in Egypt and Arab countries. Ismailia, Egypt.

El-Adawy, A. M., H. Yousri, Y. M. Ahmed, K. Tillikka and T. A. El-Sharkawy (2000). Estimation of general selective toxicity ratios of certain acaricides to Stethorus gilvifrons (Mulsant) and its prey Tetranychus urticae Koch. Egypt. J. Agric. Res. 78(3): 1081-1089.

El-Esnawy, B. A. (2006). Selectivity of certain acaricides on the predator Scolothrips longicornis: Egypt. J. of Appl. Sci., 21(10 B): 767- 774.

Sanatgar, E., V. S. Reza, A. Z. Abbas, A. Masoud and S. N. Ebrahim (2011). Effect of Frequent Application of Hexythiazox on Predatory Mite Phytoseiulus persimilis Athias - Henriot (Acari: Phytoseiidae). Academic Journal of Entomology, 4(3): 94-101. 
Finney, D. J. (1952). Probit analysis- a statistical treatment of the sigmoid response curve. Cambridge university press.

Gerson, U. and PG Weintraub (2006). Mites for the control of pests in protected cultivation. Pest Manage. Sci., pp 46.

Guirguis, M. W., I. I. Mohamed and A. M. AbdelRahman (1977). Development of resistance to Roger, Proclonol, and omite in a strain of Tetranychus arabicua Attiah in Egypt. Bull. Ent. Soc. Egypt. Econ. Ser., 10: 153 - 159.

Kim S. S. and S. S. Yoo (2002). Comparative toxicity of some acaricides to the predatory mite, Phytoseiulus persimilis and the two spotted spider mite, Tetranychus urticae. BioControl, 47: 563-573.

Kishimoto, H. (2002). Species composition and seasonal occurrence of spider mites (Acari: Tetranychidae) and their predators in Japanese pear orchards with different agrochemical spraying programs. Appl. Entomol. Zool., 37: 603-615.

Nakagawa, T. (1993). Studies on the seasonal occurrence and predatory activity of the predators of Kanzawa spider mite, Tetranychus kanzaIwaiKishida in tea fields. Bull. Saga Pref. Tea Exp. Stn., 1: 1-40 (in Japanese).

Puinean, A. M., I. Denholm, N. S. Millar, R. Nauen and M. S. Williamson (2010). Characterisation of imidacloprid resistance mechanisms in the brown planthopper, Nilaparvatalugens (Hemiptera: Delphacidae). Pestic Biochem Physiol., 97(2): 129-132.

Sarhan, A. A., A. Shoukry and Ibrahem, A.A. A. (1989). Biological studies on Stethorus gilvifrons
(Mulsant), predator of Tetranychus urticae Koch in Egypt. $3^{\text {rd }}$ Nat. Conf. Pest Dis. Veg. Fruit in Egypt and Arab Count., 408-421.

Shaw, P. B. (1982). Analysis and simulation of the population dynamics of a predator- prey system consisting of Phytoseiulus persimilis Attias Henriot (Acari: Phytoseiidae) and Tetranychus urticae Koch (Acari: Tetranychus) with particular regard to the significance of the life history parameters of both species, the functional response, the components of the numerical response, and temperature. Ph.D Thesis, University of California, Davis, California.

Sun, Y. S. (1950). Toxicity indexes an improved method of comparing the relative toxicity of insecticides. J. Econ. Entomol., 43: 45-53.

Szwejda, J. (1993). Injury symptoms and control of two spotted spider mite species: Tetranychus urticae and $T$. cinnabarinus occurring on cucumbers and tomatoes. Pruszynski, -J and Lipa, -JJ. (eds). Instytut Ochrony Roslin, Poznan (Poland). Materials of the $33^{\text {rd }}$ Research Session of Institute of Plant Protection. Pt. 1. Reports. Panstwowe Wydawnictwo Roliniczeilesne, pp. 128-135.

White J.C. (2004). Developing IPM strategies for control of two spotted mites in strawberries in north central Florida. Master's thesis. University of Florida. Gainesville, Florida, USA.

Zhang, J.Y., H. J. Chen and D.Y. Chen (2005). Studies on the hawthorn spider mite control by the combination of Scolothrips takahashii and pyridaben. Decid. Fruit, 37(4): 39-42. (In Chinese).

\section{التأثير الجاتبي لبعض مبيدات الأكاروس علي ثلاثة مفترسات لأكاروس العنكبوت الأحمر ذو البقعتين

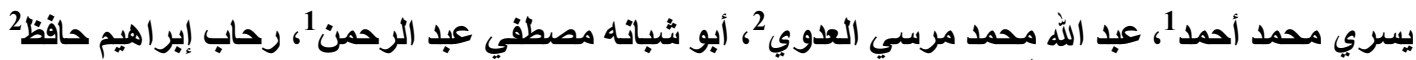

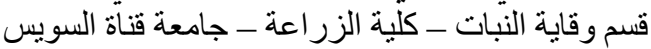

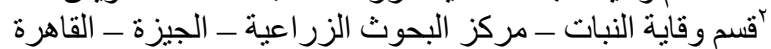

تم تقدير سمية بعض المبيدات الأكاروسية التابعة لمجاميع كيميائيه متنوعة (الايثيون وبيفينز ات وكلورفينبير و أبامكيتن ودايفنيثريون

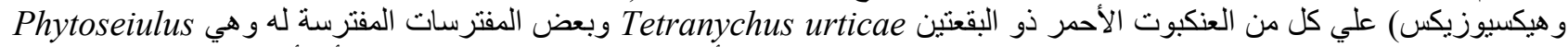
(أوضحت النتائج المتحصل عليها أن أبامكينن (rorsimilis, Scolothrips longicornis, Stethorus gilvifrons

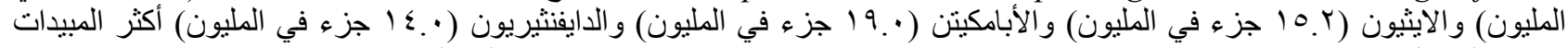

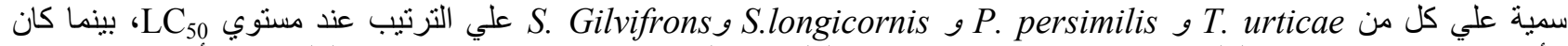

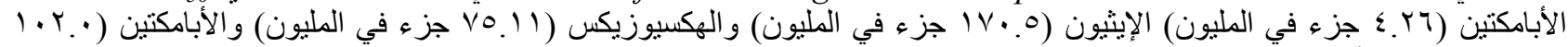

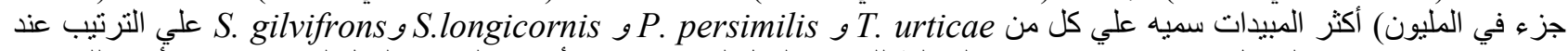

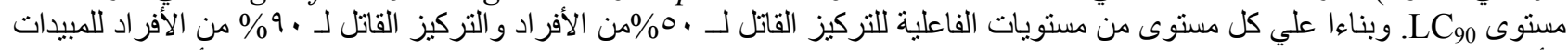

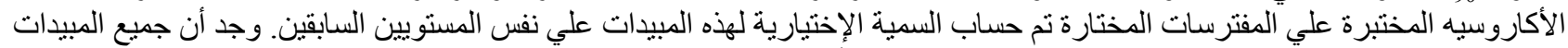

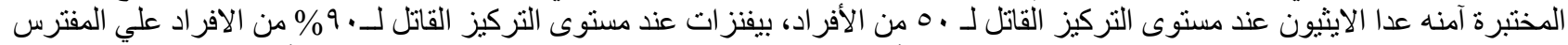
كانا منين عimilis

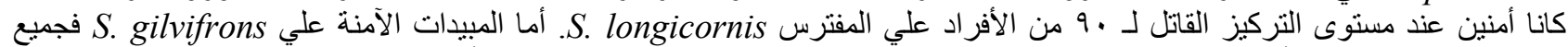

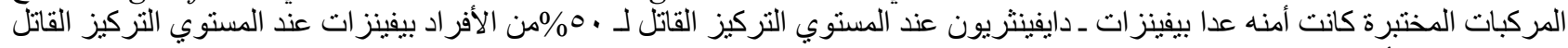

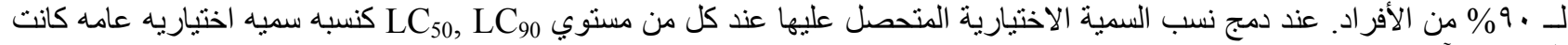

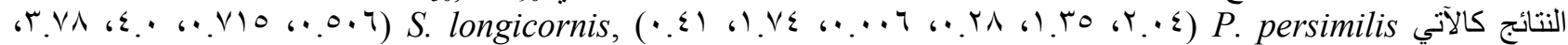

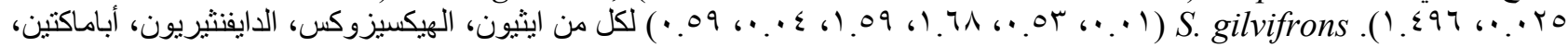

